\title{
FINITE ELEMENT ANALYSIS OF OUT-OF-PLANE BENDING OF PRECAST CONCRETE SANDWICH PANELS
}

\author{
Mohamed F. Gomaa \\ Senior Structural Engineer and PhD Candidate, Cairo University, Cairo, Egypt \\ Walid A. Attia and Ahmed H. Amer \\ Professor of Structural Engineering, Cairo University, Cairo, Egypt
}

\begin{abstract}
The objective of this paper is to develop a finite element analysis modeling capable to estimate the behavior of precast concrete sandwich panels (PCSP), such as ultimate and working loads of the panel, load-deflection relationship of the panel, axial force in shear connectors, and stresses at any point of the sandwich panel components, under out-of-plane bending effect. A nonlinear finite element analysis of PCSP was developed using ANSYS software, V18.2 [1], and validated against published test data. Using the verified model, a simple parametric study was carried out to investigate the effect of some parameters: bond of insulation layer with concrete wythes, use of GFRP and steel materials in shear connectors. The finite element analysis results showed a good agreement with the published test results, and the developed model is capable to capture the effect of foam core bond and the effect of shear connector materials.
\end{abstract}

Keywords: Concrete, concrete sandwich panel, insulated panels, flexural capacity of precast concrete panels.

Cite this Article: Mohamed F. Gomaa, Walid A. Attia and Ahmed H. Amer, Finite Element Analysis of Out-of-Plane Bending of Precast Concrete Sandwich Panels. International Journal of Civil Engineering and Technology, 11(2), 2020, 101-113.

https://iaeme.com/Home/issue/IJCIET?Volume=11\&Issue=2

\section{INTRODUCTION}

Precast concrete sandwich panels (PCSP) are composed of two concrete layers, known as wythes, separated by a rigid layer of insulation [2] (foam core) which reduces the space heating and cooling costs of the structures. The structural out-of-plane bending behavior of sandwich panels depends heavily on the degree of composite action that is influenced by the interface shear force transferred between the wythes, based on the efficiency of the provided shear connectors. Fully composite and non-composite panels can be readily analyzed, but there is uncertainty in evaluating partially composite panels due to the complex nature of such elements. 
Non-composite walls have no shear transfer between the concrete wythes and they work independently, while the fully composite wall has a full transfer of shear force between the wythes that makes them act as a one unit. The partially composite panel acts in a manner between both these extremes of non-composite and fully composite.

In this paper, a 3D finite element modeling using ANSYS software [1] was developed in order to estimate the out-of-plane bending behavior of sandwich panel. The accuracy of the developed model was verified against the results of previous experimental work carried out by Tomlinson, D., and Fam, A., 2015 [3].

\section{FINITE ELEMENT MODEL (VALIDATION MODEL)}

The present study utilized the finite element program, ANSYS version 18.2 [1], to simulate the behavior of the precast concrete sandwich panel. Three dimensional finite element model was carried out to simulate the geometry, materials, loading, and boundary conditions of the panels.

\subsection{Element Types}

The elements types that used in the analysis can be summarized as follows: concrete wythes were modelled using a three dimensional solid element with 8 nodes and three degrees of freedom at each node (solid 65). The most important aspect of this element is the ability to consider the cracking and crushing behavior of concrete material according to pre-defined failure criteria of the upper stress limits (tension and compression) of the concrete material used in the analysis along with the shear transfer coefficients for open and closed cracks $(0.3$ and 0.9 respectively).

The insulation layer of expanded polystyrene material (EPS) was simulated as 3D solid element having 8 nodes with three degrees of freedom at each node (solid 185), which is a general solid element and recommended for plasticity models that can consider both linear and nonlinear properties of the simulated material (elastic-plastic hardening).

Shear connectors and steel reinforcement embedded in the concrete were simulated as a 3D spar elements (Link180) with 2 nodes. The element is a uniaxial tension-compression element with three degrees of freedom at each node. Both tension-only (cable) and compression-only (gap) options are supported. Link 180 doesn't consider any bending through it.

The interface between the concrete wythes and EPS was modelled as fully bonded with the concrete, as reported in the experimental work (validation model). To avoid stress concentration problems at supporting locations, a 3D solid elements of 8 nodes (solid 185) with elastic properties were used as bearing pads during the loading process. Figure 1 shows the $3 \mathrm{D}$ view of the validation model along with the typical elements used for modelling in this study.

\subsection{Material Modelling}

Further to the aforementioned 3D elements types, the assigned materials are concrete, steel reinforcement, expanded polystyrene for insulation layer.

\subsubsection{Concrete Material}

Further to the aforementioned failure criteria, which combined with element type (solid-65) that defines the cracking and crushing stresses limits of the concrete material, the uniaxial stress-strain relationship for concrete in compression is required for ANSYS [1] as an input. The relation was defined as a multi-linear curve composed of eleven points as shown in Fig. 2. The concrete was assumed to be homogeneous and initially isotropic. The tensile behavior 
of concrete was assumed to be linear up to cracking stress (tensile stress will drop to zero after the cracking, conventional concrete).

\subsubsection{Steel Reinforcement Material}

Steel reinforcement is defined as a bilinear relationship with initial elastic modulus of $2 \mathrm{E}+05$ $\mathrm{MPa}$ and yielding stress of $485 \mathrm{MPa}$ for the validation model as reported in the published test data [3]. The compression strength of the steel connectors was reduced to consider the slenderness effect $(\mathrm{KL} / \mathrm{r})$, however the tensile strength was based on the full yielding stress.

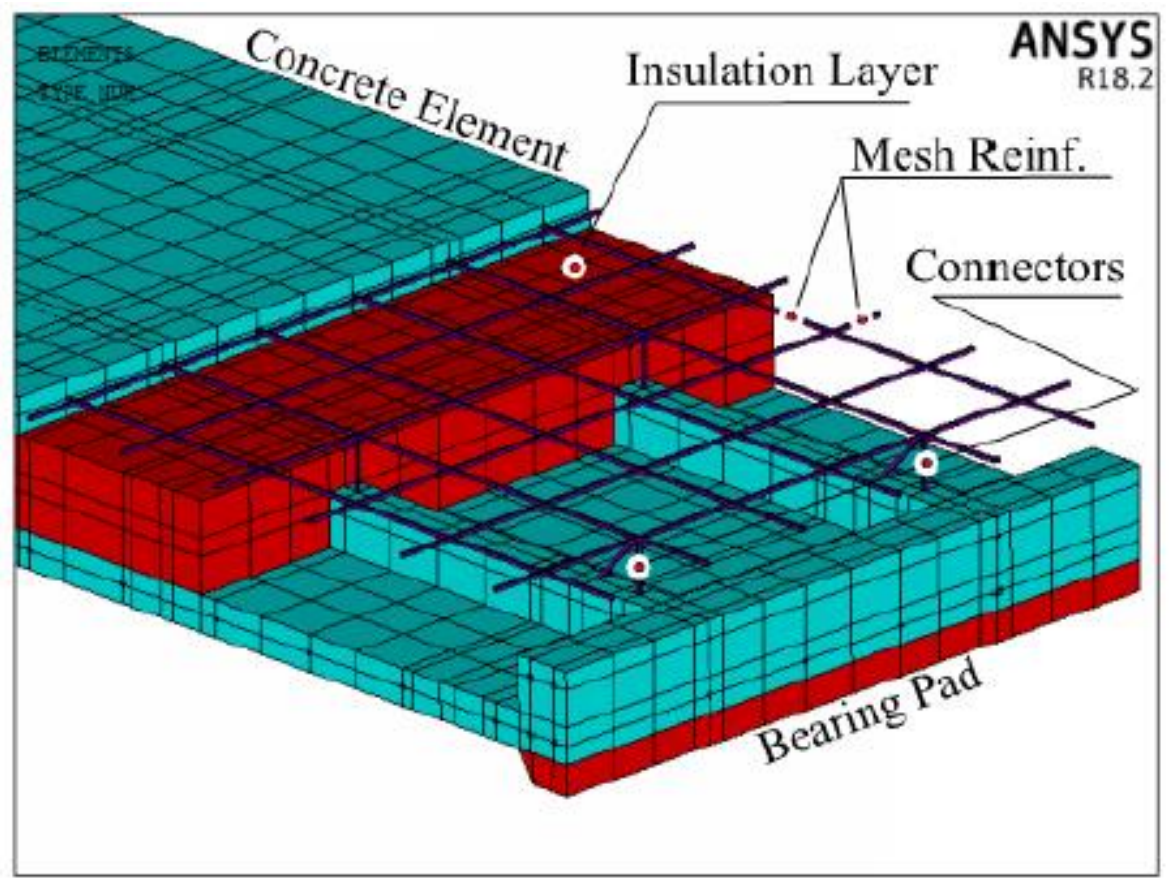

Figure $13 D$ View of the validation model.

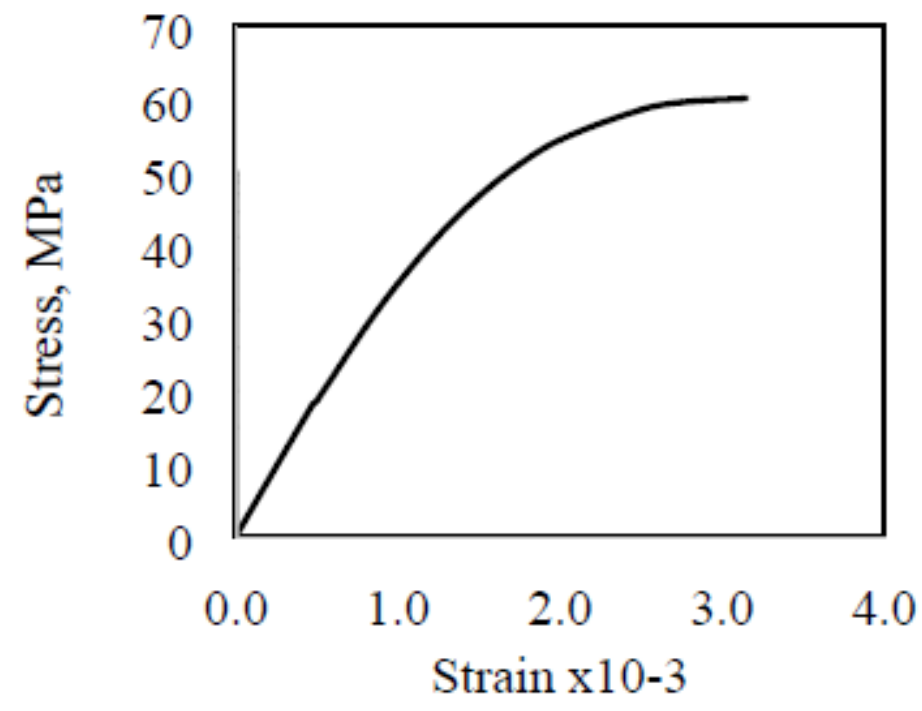

Figure 2. Uniaxial compressive stress- strain relationship for concrete with $\mathrm{fc}^{\prime}=60 \mathrm{MPa}$ (validation model). 


\subsubsection{Expanded Polystyrene for Insulation Material (EPS)}

The insulation used was expanded polystyrene foam with a yield strength of $122 \mathrm{KPa}$ at $1.67 \%$ strain, modulus of elasticity of $9.2 \mathrm{MPa}$, and a shear modulus of 5.7 MPa. The insulation has a density of $27 \mathrm{~kg} / \mathrm{m} 3$ [3]. Figure 3 shows the stress-strain relationship of the insulation material under compression load. The tensile behavior of EPS is assumed to be linear up to rupture at tensile strength of $0.2 \mathrm{MPa}$, as found in the literature (conservative value was assumed, as the tensile strength of EPS has a wide range).

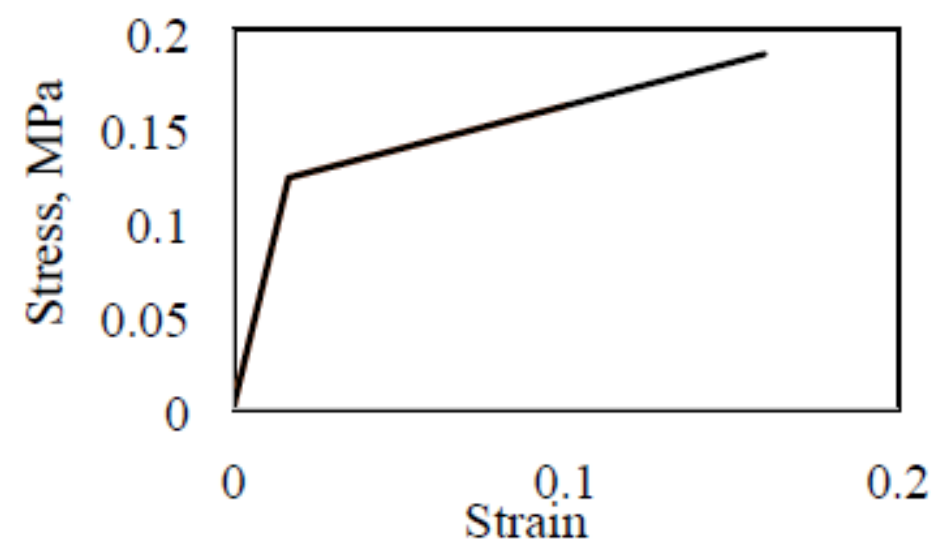

Figure 3. Simplified uniaxial stress- strain relationship of insulation material.

\section{ANALYSIS AND DISCUSSION OF THE VALIDATION MODEL}

The accuracy of the developed finite element model (FEM) was verified by means of experimental data to ensure its validity and the degree of accuracy. In this section, the 3D FEM based on the previous criteria of the elements' types and materials data was analyzed, and the finite element model's results were compared with the corresponding experimental data. The tested panel was simply supported with a span of $2630 \mathrm{~mm}, 1200 \mathrm{~mm}$ width, and $270 \mathrm{~mm}$ thickness [3].
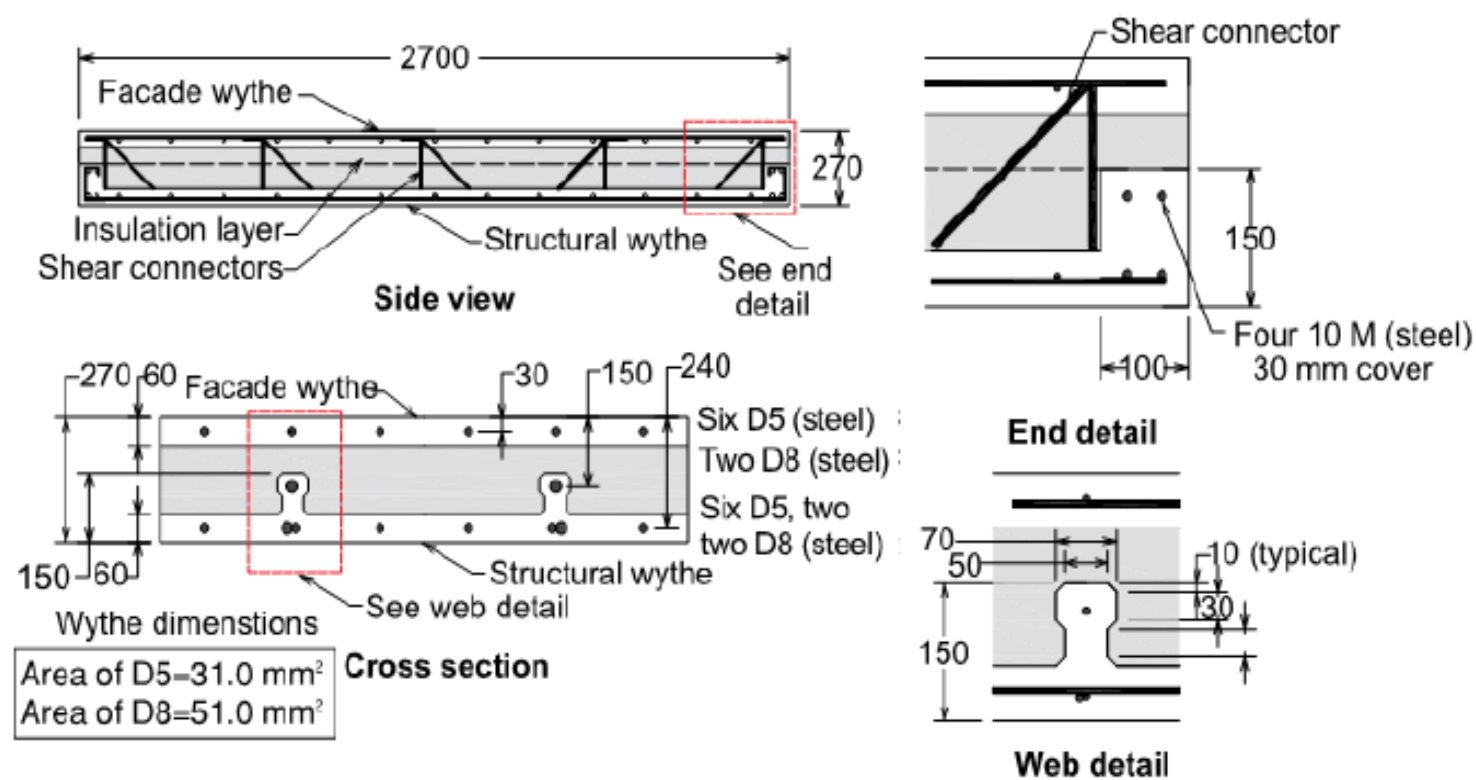

Figure 4 Geometry of the tested panel and its details [3]. 
The concrete used in the panel was self-consolidating with a design 28-day compressive strength of $60 \mathrm{MPa}$. Steel used for the shear connectors and flexural reinforcement was made from deformed bars with a yield strength of $485 \mathrm{MPa}$, ultimate strength of $650 \mathrm{MPa}$. The insulation foam (EPS) material was as previously mentioned in the materials criteria with elastic modulus of $9.2 \mathrm{MPa}$, and yielding stress of $122 \mathrm{KPa}$.

The geometry of the tested panel, connectors details, and loading setup are as shown in Fig. 4, 5 and 6 respectively, as reported in the published test data. Figure 7 shows the loaddeflection relationships of the experimental work.
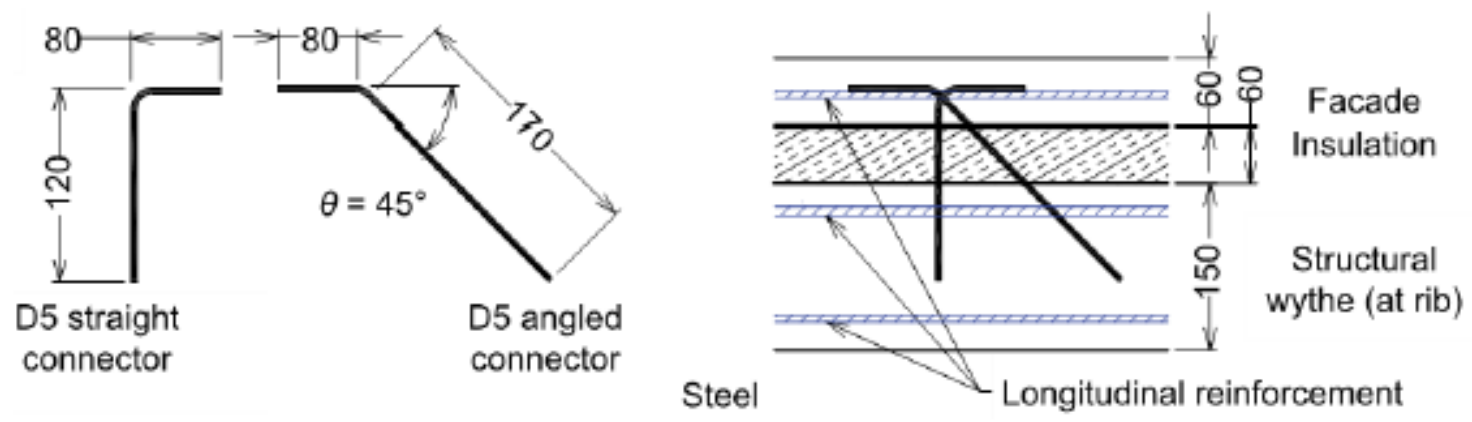

Figure 5 Steel connectors details [3].

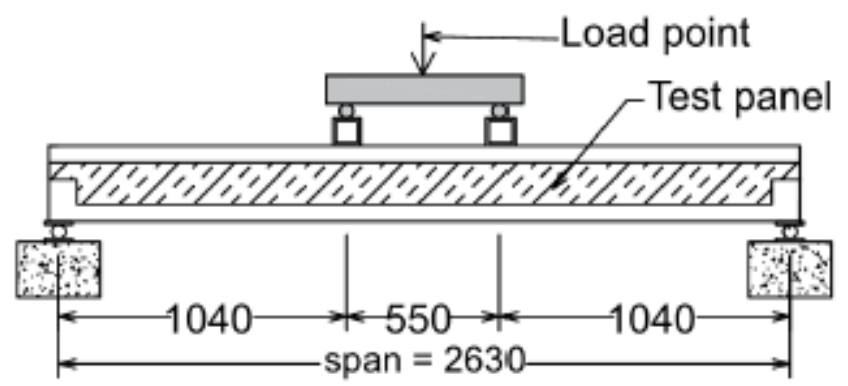

Figure 6. Loading setup [3].

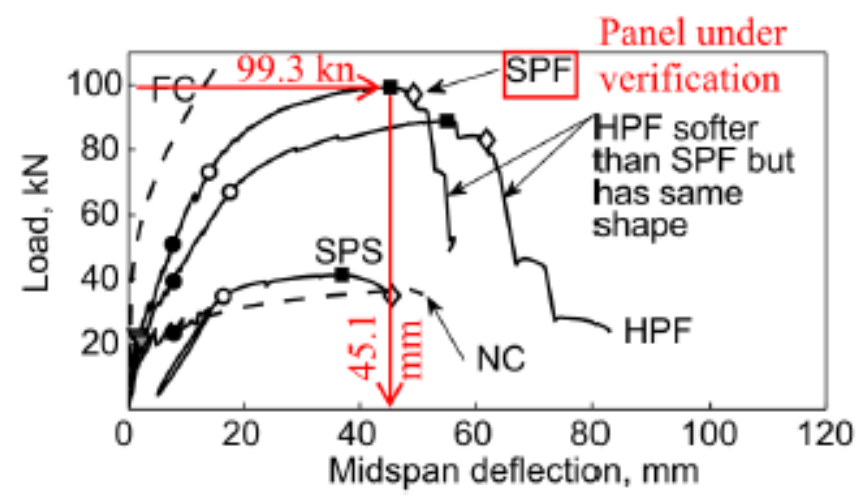

Figure 7. Experimental load-deflection relationships of the tested panels [3]. 
Finite Element Analysis of Out-of-Plane Bending of Precast Concrete Sandwich Panels

\subsection{Validation Model Results}

Figures from 8 to 10 show the stress in steel reinforcement, top concrete wythe, and bottom concrete wythe. Figure 11 shows the ultimate deformed shape of the validation model, and fig. 12 shows the analytical load-deflection relationship of the validation model at mid span.

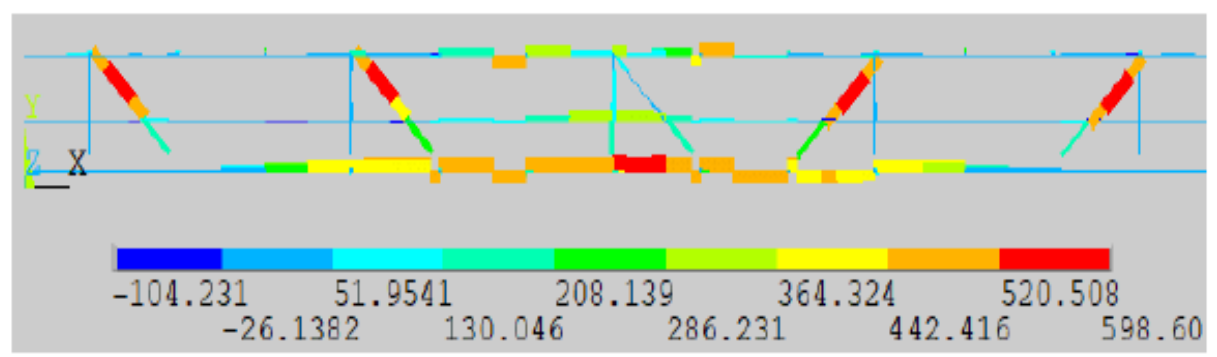

Figure 8. Stresses of reinforcement at ultimate load, MPa.

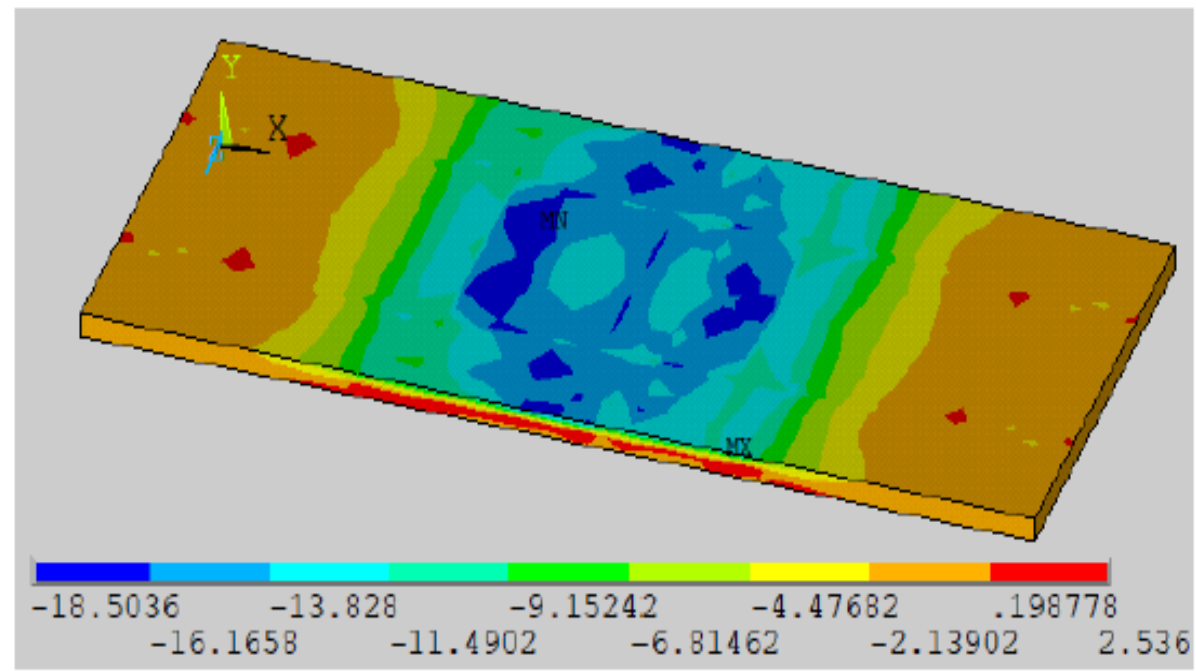

Figure 9. Normal stresses of top concrete wythe at ultimate load, MPa.

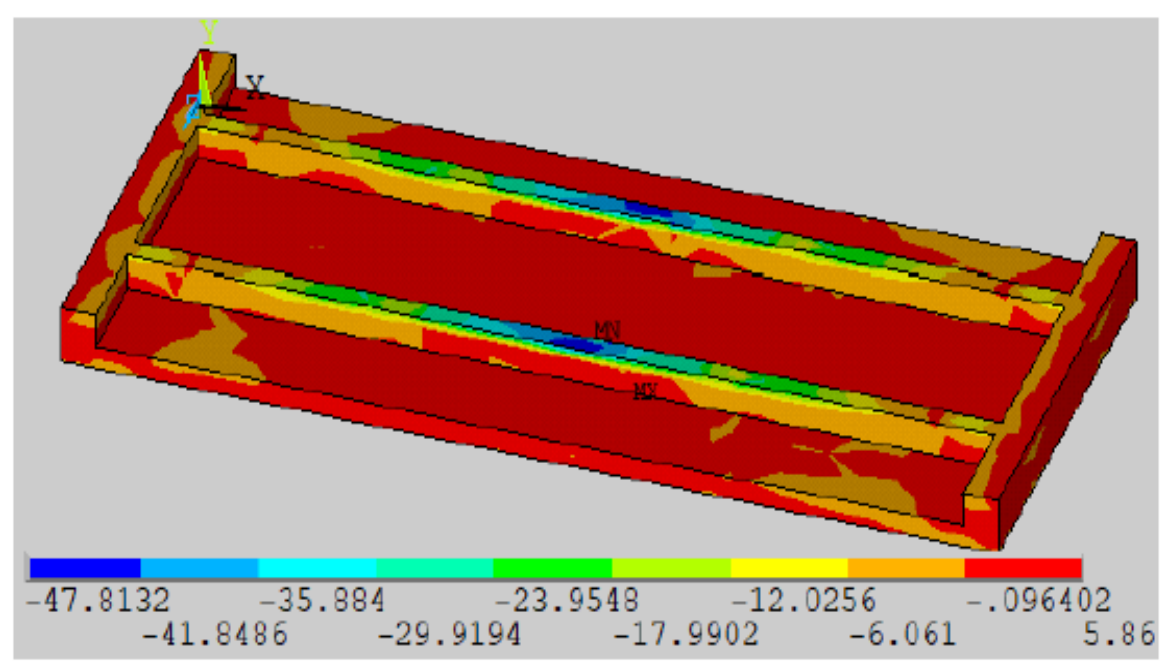

Figure 10. Normal stresses of bottom concrete wythe at ultimate load, MPa. 


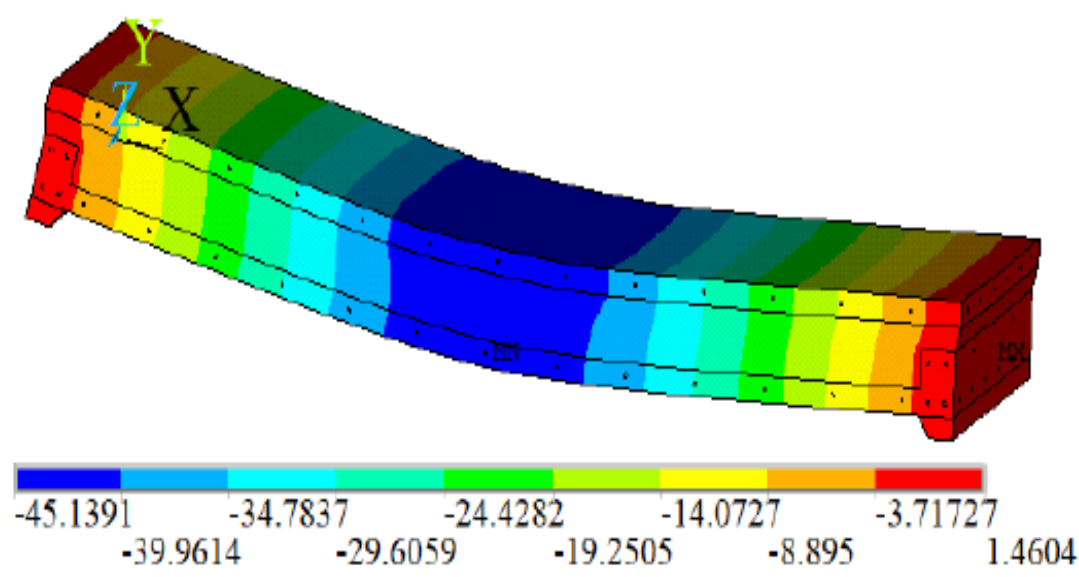

Figure 11. Ultimate deformed shape for the FEM of the tested Panel, mm.

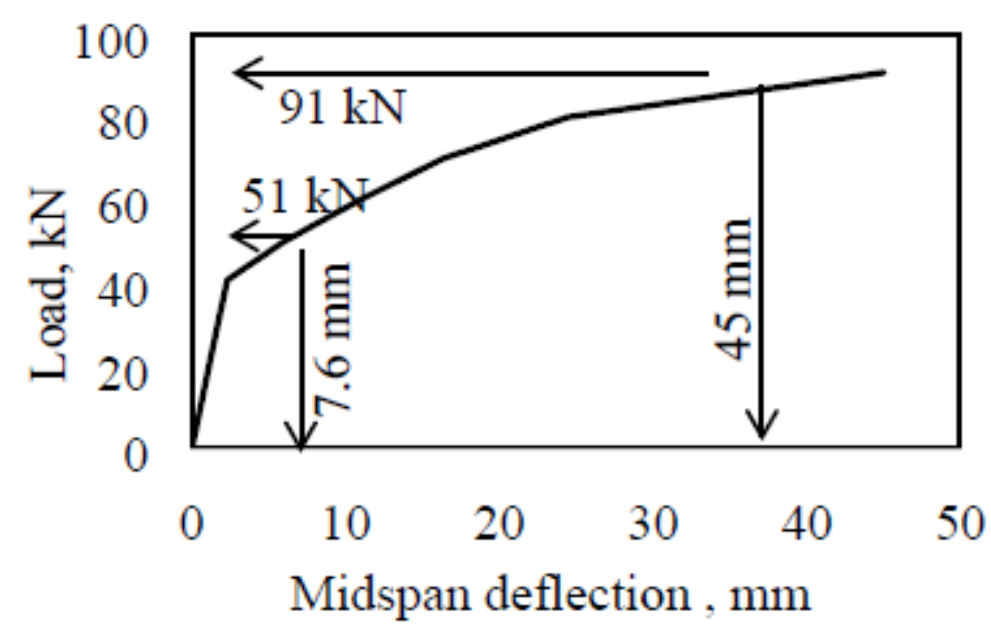

Figure 12. Analytical load-deflection relationship of the tested Panel.

\section{PARAMETRIC STUDY}

Using the verified model, a parametric study based on six panels were carried out to investigate the flexural behavior of the PCSP using steel shear connector, GFRP connector, and study the effect of foam bond in composite action. Table 1 and figs. from 13 to 18 clarify the configurations of the six panels, and figure 19 shows the elevation view of the FEM of sandwich panel SP-2.

It is noteworthy that SP-1 and SP-5 represent the two extreme actions of fully composite and non-composite panels respectively. SP-1 is composed of two concrete wythes connected by rigid ribs, and SP-5 is a sandwich panel composed of two concrete wythes separated by a rigid insulation layer, and the insulation layer is not bonded with concrete, which was applied by using frictionless contact surfaces to exclude the insulation layer from transferring the horizontal shear stresses at the interfaces. 
Finite Element Analysis of Out-of-Plane Bending of Precast Concrete Sandwich Panels

Table 1 Characteristics of panels in the parametric study.

\begin{tabular}{|c|c|c|c|c|c|c|c|c|c|c|c|}
\hline \multirow{3}{*}{$\begin{array}{c}\text { ITEM } \\
\text { No. }\end{array}$} & \multirow{3}{*}{ Model } & \multirow[b]{2}{*}{ Span } & \multicolumn{2}{|c|}{ Internal Layer } & \multicolumn{2}{|c|}{ External } & \multirow{3}{*}{$\begin{array}{l}\text { Panel } \\
\text { Detail } \\
\text { Type }\end{array}$} & \multicolumn{3}{|c|}{ Shear Connectors } & \multirow{3}{*}{$\begin{array}{l}\text { Interface } \\
\text { condition }^{\mathrm{a}}\end{array}$} \\
\hline & & & $\begin{array}{c}\text { Thick- } \\
\text { ness }\end{array}$ & fc' & $\begin{array}{c}\text { Thick- } \\
\text { ness }\end{array}$ & fc' & & $\begin{array}{c}\text { Material } \\
\& \mathrm{Fy}\end{array}$ & Dia. & Ratio $^{b}$ & \\
\hline & & $\mathrm{m}$ & $\mathrm{mm}$ & $\mathrm{MPa}$ & $\mathrm{mm}$ & $\mathrm{MPa}$ & & $\mathrm{MPa}$ & $\mathrm{mm}$ & $\%$ & \\
\hline 1 & SP-1 & \multirow{6}{*}{$\mathrm{m}$} & \multirow{6}{*}{$\stackrel{2}{=}$} & \multirow{6}{*}{ 웅 } & \multirow{6}{*}{$\approx$} & \multirow{6}{*}{ \& } & (1), Fig. 13 & \multicolumn{3}{|c|}{ Rigid Concrete Ribs } & - \\
\hline 2 & SP-2 & & & & & & \multirow{2}{*}{ (2), Fig. 14} & \multirow{2}{*}{\multicolumn{2}{|c|}{\begin{tabular}{c|c}
$\begin{array}{c}\text { Steel, } \\
420\end{array}$ & 6 \\
\end{tabular}}} & 0.025 & Fully Bonded \\
\hline 3 & SP-3 & & & & & & & & & 0.025 & No Bond \\
\hline 4 & SP-4 & & & & & & \multirow{2}{*}{ (3), Fig. 15} & \multirow{2}{*}{--} & \multirow{2}{*}{--} & \multirow{2}{*}{--} & Fully Bonded \\
\hline 5 & SP-5 & & & & & & & & & & No Bond \\
\hline 6 & SP-6 & & & & & & (2), Fig. 14 & $\begin{array}{l}\text { Fibers, } \\
\text { GFRP }\end{array}$ & 6 & 0.025 & Fully Bonded \\
\hline
\end{tabular}

a- The interface condition represents the interface between the concrete wythes and insulation layer.

b- The ratio of shear connectors represents the total shear connectors area per interface area.

c- GFRP represents the glass fiber reinforced polymer with tensile strength of $970 \mathrm{Mpa}$ (tension only).

All concrete wythes in all panels are reinforced with deformed steel bars with yield stress of $420 \mathrm{MPa}$.

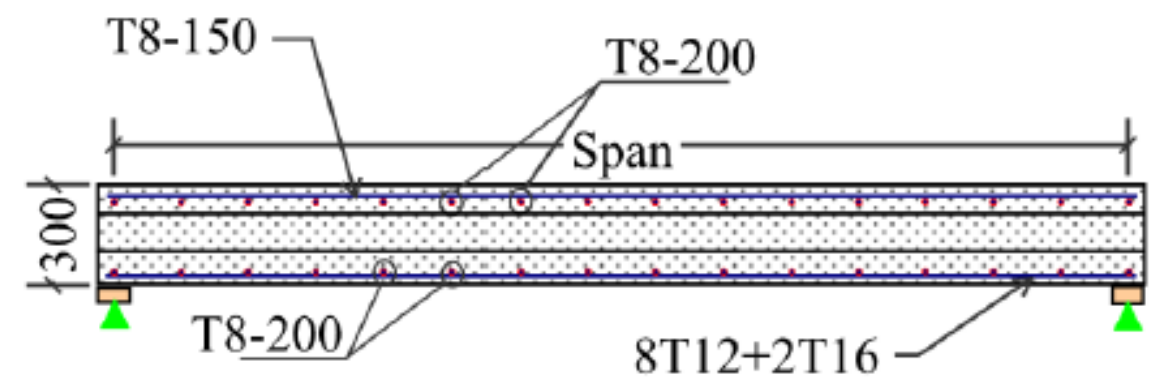

Figure 13. Panel type 1, fully composite (side view).

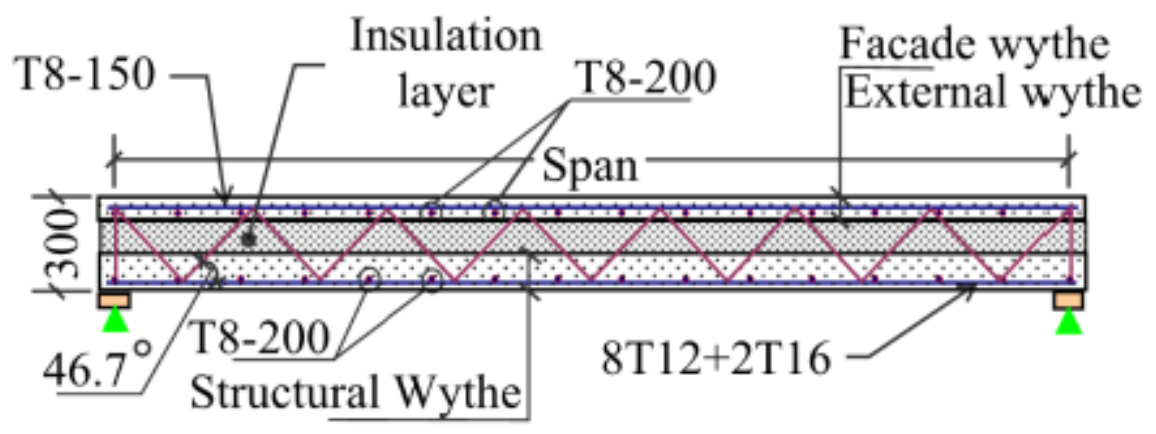

Figure 14. Panel type 2, sandwich panel (side view).

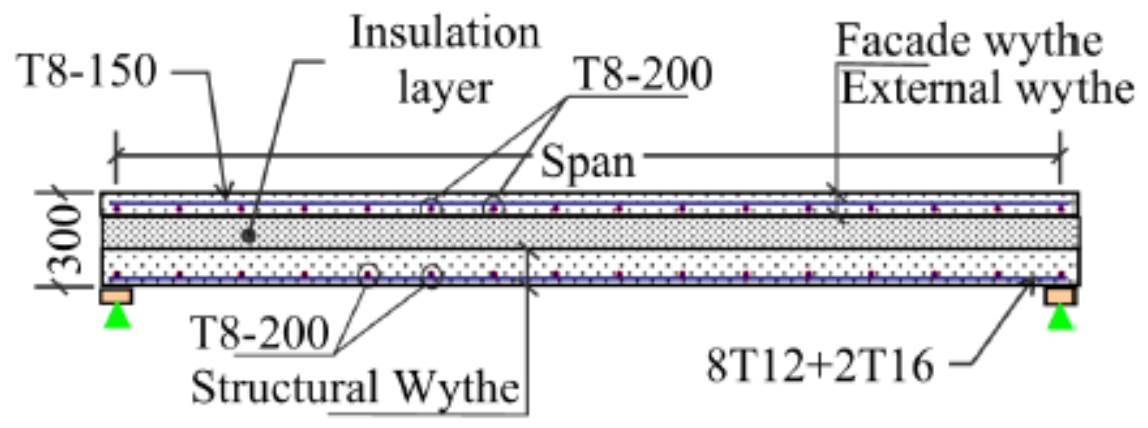

Figure 15. Panel type 3, sandwich panel (side view). 


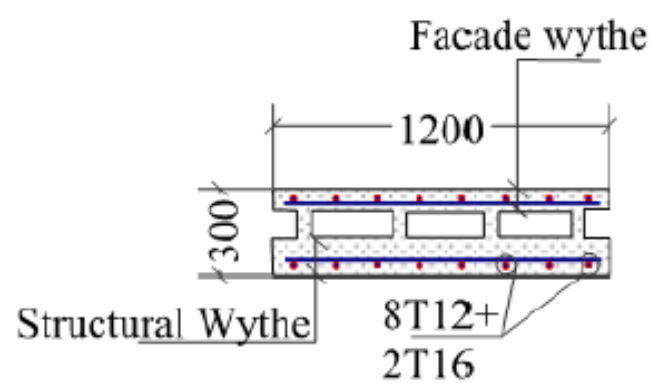

Figure 16. Cross section of panel type 1.

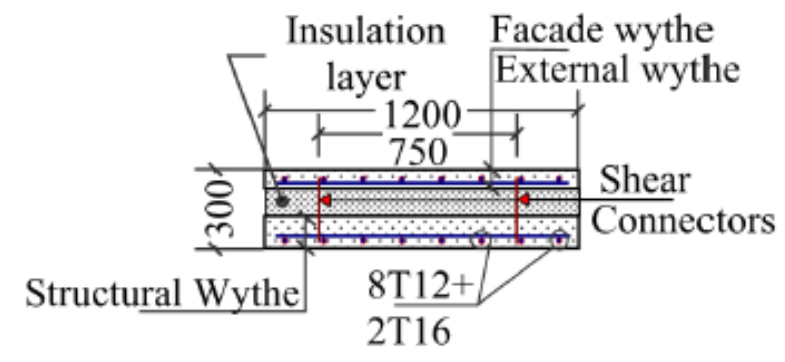

Figure 17. Cross section of panel type 2.

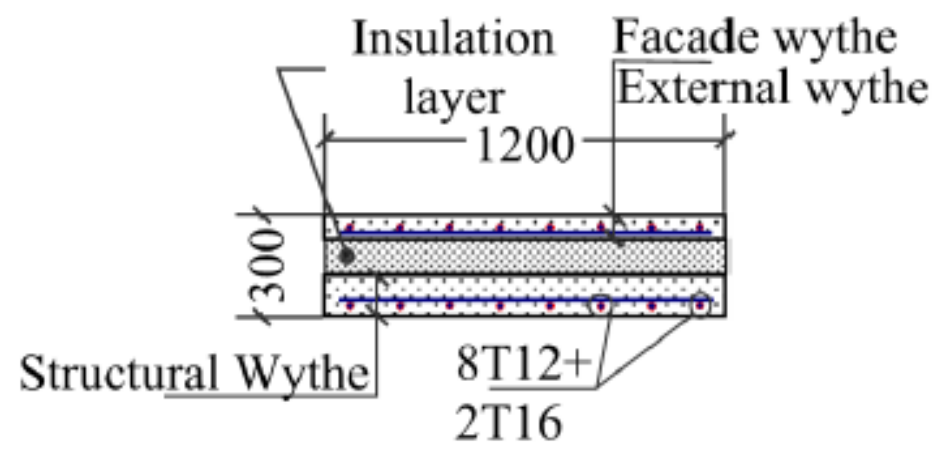

Figure 18. Cross section of panel type 3.

All panels were loaded with a uniformly distributed load, as shown in Fig. 20, to investigate the effect of wind pressure load on a vertical cladding wall. All panels had a total thickness of $300 \mathrm{~mm}$. The insulation layer was $100 \mathrm{~mm}$ in all sandwich panels. The clear concrete cover was $30 \mathrm{~mm}$ for all panels.

\section{RESULTS AND DISCUSSION}

\subsection{Load-Deflection Relationships}

The deflection of the modeled panels was recorded at mid span and the maximum deflection plotted against the total applied load $(\mathrm{kN})$ from zero loading up to failure as shown in Figure 23. Figures 21 and 22 show the deformed shape of panels SP1 and SP5.

\subsection{Service Load}

The maximum allowed service wind load for each panel was determined to be the lowest value given by two commonly used constraints: the first constraint is from strength, which unfactors the ultimate load UL using the UL equal to 1.2DL+1.6 WL +1.0L load factors in the ACI 318 building Code [4], taking into consideration that concentric self-weight has no significant effect on out-of-plane bending for cladding walls and only wind load will induce the bending moment in the out-of-plane direction. The second constraint is mid-height defection limit from lateral wind load, to L/150 according to ACI 318 building Code [4].

Tables 2 summarizes the service load values for all panels using these two conditions.

It should be noted that all loads mentioned in the tables are the total loads in $\mathrm{kN}$. 


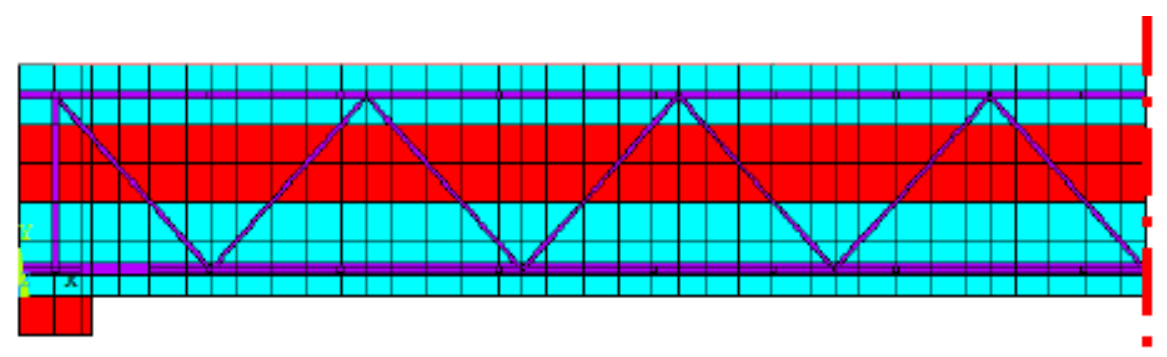

Figure 19. FEM of sandwich panel SP-2.

\subsection{Key Results from Flexural Analysis}

Tables 3 summarizes the results of the modeled panels. The results are shown in terms of ultimate, service, and cracking loads along with the associated deflections.

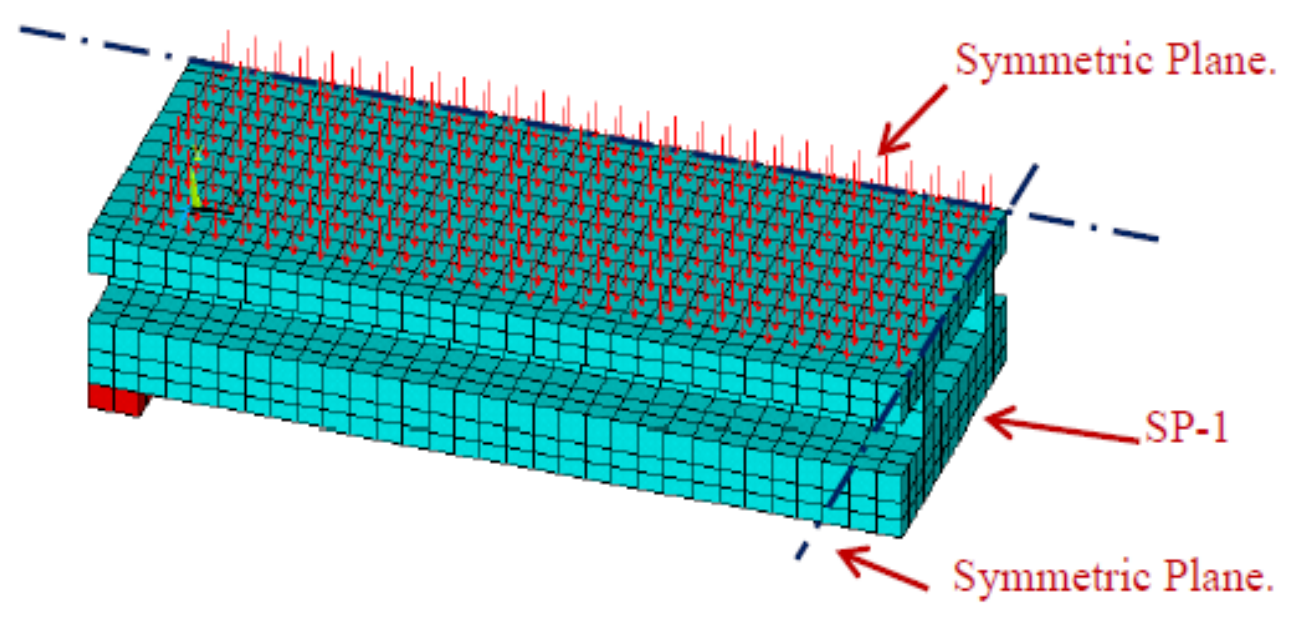

Figure 20. Typical loading for the modeled panels, quarter panel (uniform load).

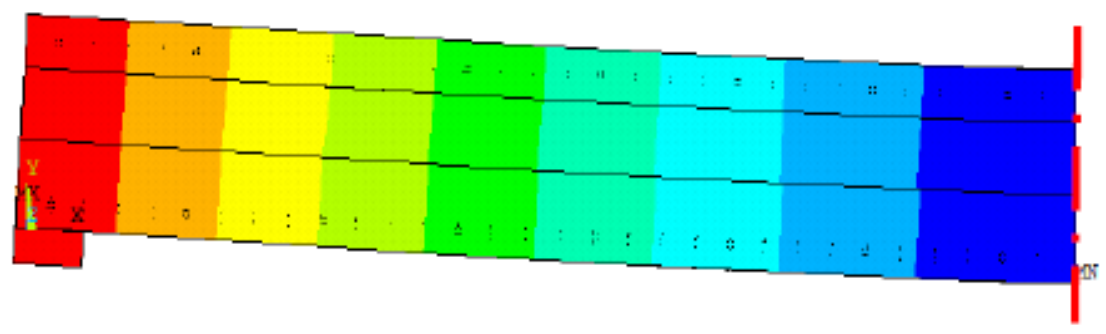

Figure 21. Deformed shape of composite panel, SP-1.

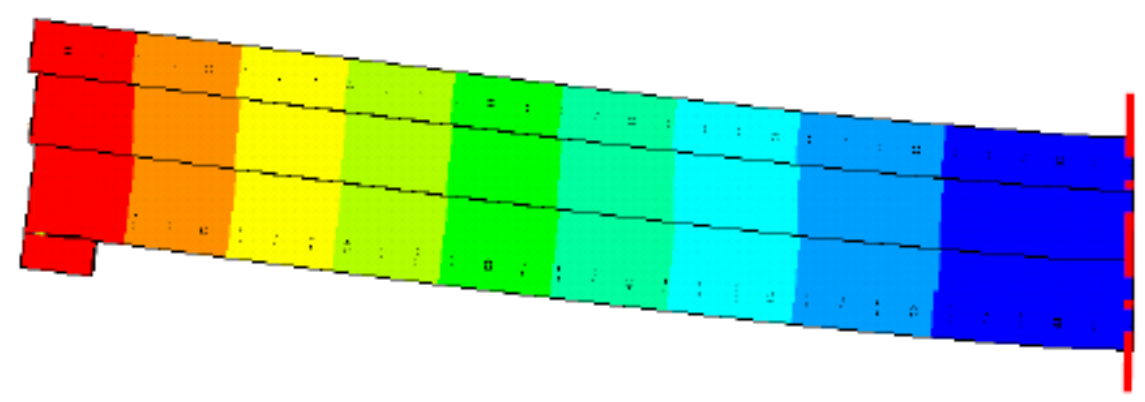

Figure 22. Deformed shape of non-composite panel, SP-5. 


\subsection{Assessment of Composite Action Level}

The composite action $(\mathrm{K})$ by load was evaluated at ultimate, working and cracking loads for each panel using the following equation:

$$
K=\frac{P_{p}-P_{n c}}{P_{f c}-P_{n c}} \times 100
$$

Where,

$\mathrm{P}_{\mathrm{p}}=$ observed model load.

$\mathrm{P}_{\mathrm{nc}}=$ non-composite capacity $(\mathrm{SP}-5)$.

$\mathrm{P}_{\mathrm{fc}}=$ fully composite capacity $(\mathrm{SP}-1)$.

Tables 3 shows the degrees of composite action in terms of ultimate, service, and cracking.

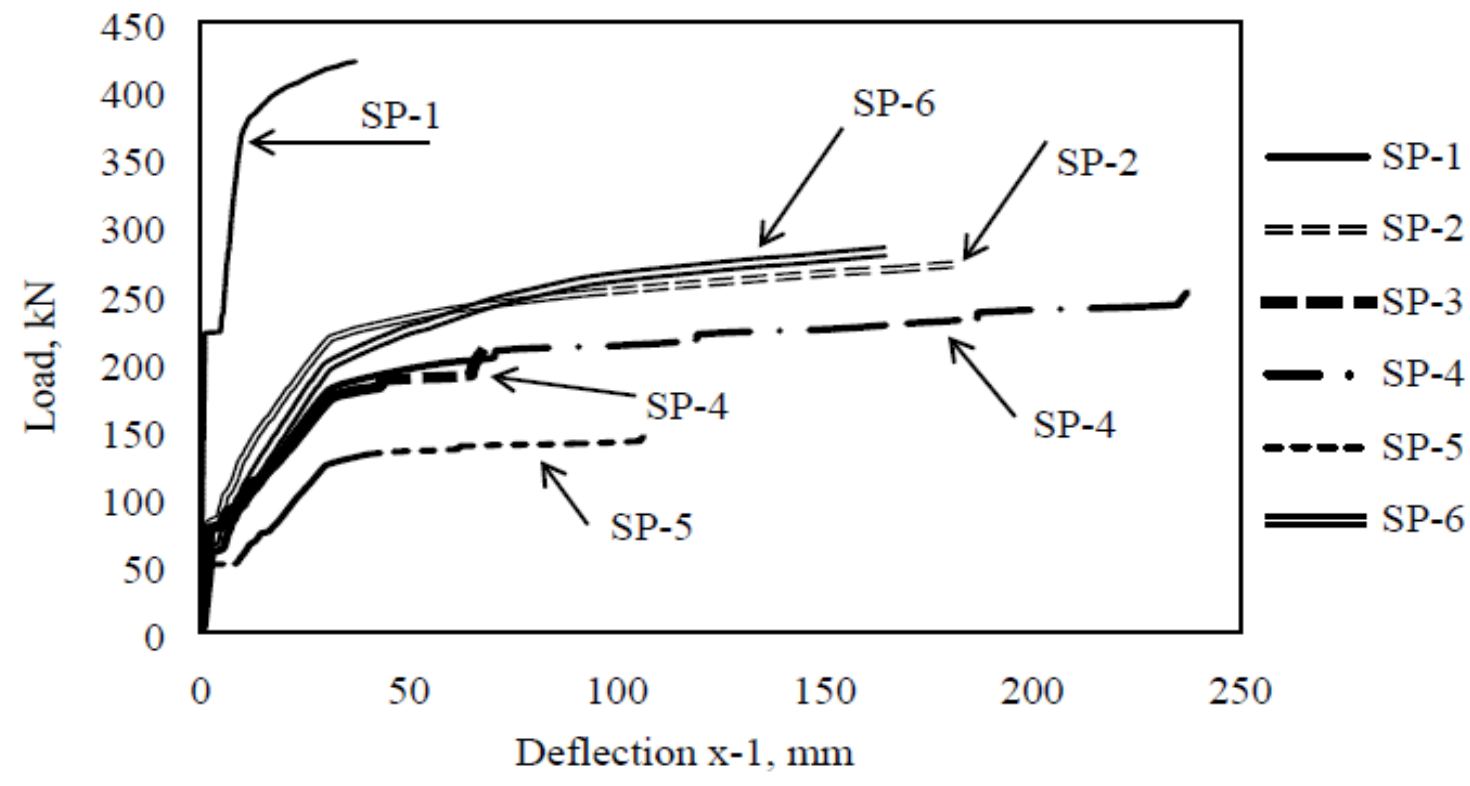

Figure 23. Load-deflection relationships of the parametric study panels.

Table 2 Service load of the parametric study panels.

\begin{tabular}{|c|c|c|c|c|c|}
\hline \multirow{2}{*}{ Model } & \multirow{2}{*}{$\begin{array}{c}\text { UT. Load, } \\
\mathrm{kN}\end{array}$} & $\begin{array}{c}\text { Back-Cal culated } \\
\text { from ultimate }\end{array}$ & $\begin{array}{c}\text { Deflection, } \\
(>\mathrm{H} / 150)\end{array}$ & $\begin{array}{c}\text { Service load, } \\
\mathrm{kN}\end{array}$ & $\begin{array}{c}\text { Service load } \\
\text { governed by: }\end{array}$ \\
\cline { 3 - 5 } & $\mathrm{L}=(\mathrm{U} / 1.6)$ & & & \\
\hline SP-1 & 421.00 & 263.125 & 400 & 263.13 & Strength \\
\hline SP-2 & 272.00 & 170 & 174 & 170.00 & Strength \\
\hline SP-3 & 206.00 & 128.75 & 130 & 128.75 & Strength \\
\hline SP-4 & 251.00 & 156.875 & 135 & 135.00 & Deflection \\
\hline SP-5 & 144.50 & 90.3125 & 87.5 & 87.50 & Deflection \\
\hline SP-6 & 281.00 & 175.625 & 149 & 149.00 & Deflection \\
\hline
\end{tabular}


Finite Element Analysis of Out-of-Plane Bending of Precast Concrete Sandwich Panels

Table 3 Results of parametric study panels.

\begin{tabular}{|c|c|c|c|c|c|c||c|c|c|}
\hline \multirow{2}{*}{ Model } & \multicolumn{3}{|c|}{ Key Load Points, $\mathrm{kN}$} & \multicolumn{3}{c||}{ Deflection, mm } & \multicolumn{3}{c|}{$\begin{array}{c}\text { Composite Action Level } \\
\text { (By Load) \% }\end{array}$} \\
\cline { 2 - 10 } & Ultimate & Service & Cracking & Ultimate & Service & Cracking & $\begin{array}{c}\text { By } \\
\text { Ultimate }\end{array}$ & $\begin{array}{c}\text { By } \\
\text { Service }\end{array}$ & $\begin{array}{c}\text { By } \\
\text { Cracking }\end{array}$ \\
\hline SP-1 & 421.00 & 263.13 & 222.00 & 37.26 & 6.03 & 4.66 & 100.00 & 100.00 & 100.00 \\
\hline SP-2 & 272.00 & 170.00 & 85.00 & 183.35 & 19.14 & 4.53 & 46.11 & 46.98 & 19.88 \\
\hline SP-3 & 206.00 & 128.75 & 80.00 & 67.34 & 19.28 & 5.22 & 22.24 & 23.49 & 16.96 \\
\hline SP-4 & 251.00 & 135.00 & 62.00 & 237.21 & 19.44 & 5.18 & 38.52 & 27.05 & 6.43 \\
\hline SP-5 & 144.50 & 87.50 & 51.00 & 106.53 & 20.07 & 8.16 & 0.00 & 0.00 & 0.00 \\
\hline SP-6 & 281.00 & 149.00 & 64.00 & 164.60 & 19.73 & 4.91 & 49.37 & 35.02 & 7.60 \\
\hline
\end{tabular}

\section{CONCLUSIONS}

\subsection{Validation Model}

The FE model used with the proposed criteria was found sufficient enough to analyze the tested specimen (Panel), from where the following results were obtained:

- The analytical ultimate load is about $92 \%$ of that of the experimental ultimate load as shown in Fig. 7, and 12.

- The analytical ultimate deformation is about $108 \%$ of that of the experimental deformation at the same load level, and about $100 \%$ of that of the experimental ultimate deformation as shown in Fig. 7, and 12.

- Both analytical and experimental deformations at service load are equal as shown in Fig. 7, and 12 .

- The analytical steel rebar's stresses at ultimate load are about $100 \%$ of that of the experimental stresses at the same load level, and about $92 \%$ of that of the experimental stresses at ultimate load.

\subsection{Parametric Study}

- Sandwich panels SP-2, SP-3, SP-4, and SP-6 of the parametric study behaved as partially composite panels.

- The participation of foam core only achieved a composite action of about $38.5 \%$ by ultimate load as found in model SP-4, However, it should be noted that the foam-concrete bond could fail from freezing and thawing, thermal, or loading cycles.

- The participation of steel truss connectors only achieved a composite action of about $22 \%$ as found in model SP-3.

- Panels with GFRP connectors had a lower stiffness at low load levels compared with the steel truss connectors, which appeared in the load deflection relationships, (Figures 23), along with the lower composite action by service and cracking loads, while the GFRP connector's panel had a higher stiffness than steel connector's panel at high load levels due to the yielding of most of steel connectors that led to lose the stiffness of the steel truss connectors at the high load levels.

- Failure of panels SP-2 and SP-6 were started by yielding of steel shear connectors and rupture of GFRP connectors respectively, then a rapid progress of normal stresses in concrete wythes were noticed until the overall failure of these panels. 


\section{REFERENCES}

[1] ANSYS Mechanical, Release 18.2, Help System, Advanced Analysis Guide, ANSYS, Inc.

[2] PCI Committee on Precast Concrete Sandwich Panels. "State of The Art of Precast/Prestressed Concrete Sandwich Wall Panels.” PCI Journal 56 (2): 131-176, 2011.

[3] Tomlinson, D., and Fam, A., "Flexural Behavior of Precast Concrete Sandwich Wall Panels with Basalt FRP and Steel Reinforcement” PCI Journal 60 (6): 51-71, 2015.

[4] American Concrete Institute (ACI). "Building Code Requirements for Structural Concrete and Commentary." ACI 318-14, 2014. 